\title{
The "New" Student-Athlete: An Exploratory Examination of Scholarship eSports Players
}

Claire C. Schaeperkoetter

University of Kansas

Jonathan Mays

University of Kansas

Sean Thomas Hyland

University of Kansas

Zach Wilkerson

University of Kansas

\author{
Brent Oja \\ University of Northern Colorado
}

Kyle Krueger

University of Kansas

Ronald Christian

Baker University

Jordan R. Bass

University of Kansas

\begin{abstract}
The growth and popularity of eSports cannot be understated. The domain has become so mainstream that colleges and universities are rapidly beginning to launch eSports programs within their athletics departments. In this study, the authors interviewed 33 student-athletes receiving scholarships for participating in eSports at one institution. In all, the identity and social capital of athletes in this "new" athletic arena were explored and compared with previous studies examining "traditional" athletes. The implications of the similarities and differences are discussed and ideas for future research into this emerging field are presented.
\end{abstract}

Keywords: student-athletes, identity, eSports

In 2014, more than 205 million people globally watched or participated in eSports (Casselman, 2015). In April of 2015, ESPN2 aired a show titled Heroes of the Dorm. The event featured the University of California-Berkeley competing against Arizona State University in a Multiplayer Online Battle Arena

Schaeperkoetter, Mays, Krueger, Wilkerson, and Bass are with the Health, Sport, and Exercise Sciences Department, University of Kansas, Lawrence, Kansas. Oja is with Sport and Exercise Science, University of Northern Colorado, Greeley, Colorado. Hyland is with Kansas Athletics, Inc, University of Kansas, Lawrence, Kansas. Christian is with Sport Management, Baker University, Baldwin City, Kansas. Address author correspondence to Jordan Bass at jrbass@ku.edu. 
(MOBA) video game called Heroes of the Storm. The broadcast was a sensation on social media with some decrying the worldwide leader in sports for airing eSports, while others were intrigued by both the gameplay and the commentators (Augustine, 2015). Defined as organized video game competitions (Jenny, Manning, Keiper, \& Orlich, 2016), eSports has gained immense popularity in youth cultures around the world since the inception of online gaming in the early 1990s (Wagner, 2007). Even more, colleges and universities are beginning to take notice, as five colleges offered eSports scholarships for the 2015-2016 academic year: Robert Morris University (IL), University of Pikeville (KY), Maryville University (MO), Southwestern University, and Columbia College (MO) (Kelly, 2015).

The potential impact that an eSports program could have on a university, coupled with the growing interest that universities are showing in such a program, combine to make this line of research relevant in sport literature. The University of Pikeville, one of five schools offering scholarships for eSports, is currently providing tuition assistance to 20 students. At Robert Morris University, 17 eSports athletes are on $70 \%$ scholarship and 16 are on $35 \%$ scholarship (Gaudiosi, 2015). Upon launching one of the first eSports programs in the country, which included a $\$ 100,000$ eSports facility, Robert Morris University's eSports program director received over 2,000 emails from interested current and prospective students and was contacted by 35 other schools (Gaudiosi, 2015). University presidents, especially those at schools with smaller enrollments, are intrigued by the ability of eSports to attract students, with the president at the University of Pikeville asserting, "In addition to being good gamers, they will be good students and will bring an exciting new dynamic to our campus" (University of Pikeville, 2014, para. 4). Although eSports are not currently sanctioned by the NAIA or NCAA, the eSports athletes in the current study are held to the same academic eligibility standards that apply to student-athletes who participate in other sports. This exploratory study into the new phenomenon of university eSports programs is focused on the athletes, their identity, and social capital. Before detailing the relevant literature on athlete identity and social capital, it is first important to describe the current organization of college-level eSports competition, to give an overview of one of the more popular eSports competitions, and to detail of the current debate surrounding the legitimacy of eSports as a real sport.

\section{North American Collegiate Championship}

Launched by the now defunct North American Challenger League, the North American Collegiate Championship (NACC) is a League of Legends (LoL) tournament administered by the game's creator-Riot Games (Kelly, 2015). While existing eSports tournaments provide prize money to participants based on where they finish, teams competing in the NACC compete for scholarship dollars ranging from $\$ 1,000$ per player up to $\$ 30,000$ for each member of the championship team. In 2015, over 1,600 teams entered the open qualifier stage, with eight teams from each conference advancing to the regular season based on winning percentage during open play. 


\section{League of Legends}

Launched in 2009 by Riot Games, LoL is a free MOBA game that enjoys tremendous popularity. In 2011, tens of millions of LoL players combined to play for more than one billion hours per month (Ferrari, 2013). Gameplay in LoL consists of two teams of five players with the ultimate objective of destroying the opponent's "nexus," a structure located inside the opposition's territory (Robertson, 2015). At the start of the game, players choose a champion to play with. Generally, each champion fills one of five positions: Attack, Damage, Carry (ADC); Support; Midlaner; Top-laner; or Jungler. Each position has general duties to fulfill and teams must strategize when to focus on individual accomplishments and when to support their teammates (Robertson, 2015).

\section{A Real Sport? The eSports Debate}

At the core of the legitimacy debate of eSports is whether eSports adheres to previously established definitions of sport. Accordingly, "the debate whether competitive video gaming (i.e., eSports) can be considered sport dates back to at least 1999, when the Online Gamers Association was launched by EuroGamer at the Sports Academy in London" (Jenny et al., 2016, p. 4). Jenny et al. (2016) examined that very issue by developing their own definition of eSports and then compared that definition to previous definitions of sport. Acknowledging the array of terms used to describe eSports (e.g., electronic sports, cybersports, gaming, competitive computer gaming, virtual sports), eSports was defined as "organized video game competitions" (Jenny et al., 2016, p. 4). Moreover, Jenny and colleagues (2016) combined Guttmann's (1978) and Suits' (2007) definitions of sport and discussed how seven of those characteristics help address whether eSports should be considered a sport: must include play, must be organized, must be comprised of skill, must include physical skill, must have a broad following, and must have achieved institutional stability. It is argued that eSports clearly meets five of the characteristics (includes play, is organized, includes competition, comprises skill, and has a broad following). The central debatable characteristics of eSports qualifying as a true sport are whether it includes physical skills and whether it has achieved institutional stability (Jenny et al., 2016).

While the physical skill required for eSports may be less obvious than in traditional sports, Jonasson and Thiborg (2010) argued that, "eSports will definitely fill a void in the sports family; no sport requires such a diversified coordination of the fingers as eSport(s)" (p. 290). The necessity of fine motor skills to excel in eSports is similar to the fine motor sports needed to excel in more traditional sports (e.g., angling a tennis racket to hit a ball or altering the wrist motion on a basketball shot attempt) (Jenny et al., 2016). However, it is acknowledged that while more traditional sports necessitate the use of fine motor skills, there are usually gross motor movements (e.g., running, jumping, etc.) required as well (Jenny et al., 2016). eSports athletes may conduct 400 movements per minute using the keyboard and mouse, they produce cortisol during competition at similar levels as a racecar driver, and have pulse rates similar to competitive marathon runners (Schütz, 2016). However, eSports is still widely viewed as an unhealthy activity, which acts as an additional barrier for its acceptance as a sport (Jonasson \& Thiborg, 2010). 
The debate as to whether eSports meets the requirement of achieving institutional stability to be characterized as a sport (Jenny et al., 2016) is seemingly in conflict with the idea that there are multiple commercial enterprises competing for increasing eSports revenue (Jenny et al., 2016; Tassi, 2014; Taylor, 2012). As such, the current governing bodies in eSports-Major League Gaming, the Cyberathlete Professional League, and the International eSports Federation-are competing from a commercial standpoint (Jenny et al., 2016). Further, because of the infancy of eSports in comparison with more traditional sports, "the competition to gain control of the eSports competitive structure will continue to escalate" (Jenny et al., 2016, p. 14). Lastly, traditional governing bodies such as the National Collegiate Athletic Association (NCAA) and the National Association of Intercollegiate Athletics (NAIA) largely have control over rule changes and standardization of the sports in which they sponsor. In eSports, however, the rules of play for each game are actually standardized by the video game developers, making it even more difficult for a governing structure of eSports to stabilize (Jenny et al., 2016).

Despite the lack of an overarching governing body for eSports (either at the professional or amateur level), colleges and universities have continued to add eSports programs, prompting one college president to state, "eSports aren't the future, they're the present. True skill at video gaming is just as impressive - and just as legitimate - as excellence in traditional sports" (Good, 2015, para. 4). With its high level of organization, spectatorship, and sponsorship, eSports makes a strong claim to be defined within the hegemony of sport. Coakley (2007) asserted that society will decide the realm in which eSports exists by emphasizing, "People will create the future of sport; fate, computer forecasts, supernatural forces, or the predictions of sociologists will not determine the future" (p. 566). Overall, the purpose of this study is to explore the role of athlete identity and social capital in relation to current eSports scholarship athletes. Specifically, it expands athlete identity and social capital literature into the sport setting while simultaneously expanding the understanding of the concepts within the eSports environment.

\section{Literature Review}

With an understanding of the current setting of eSports, it is now essential to discuss the tenets of athlete identity and social capital. Doing so helps to contextualize the role of each in relation to the present state of eSports and provides further justification for the exploratory nature of this study.

\section{Athlete Identity}

One's athlete identity is defined as "the degree to which an individual identifies with the athlete role" (Brewer, Van Raalte, \& Linder, 1993, p. 237). Restated, when individuals consider themselves to be athletes, they take on such a definition to describe themselves. Some resulting behaviors are a reflection of an individual's self-definition and are a mechanism to reaffirm the relevant identity. For example, an athlete might dress in team or athletics department apparel even when not competing to support their athlete identity. The presence of an athlete identity signifies that being an athlete is important to the individual. Moreover, identifying as an athlete might have different facets. While Brewer et al. (1993) conceptualized 
athlete identity as a unidimensional construct, others have viewed the variable as multidimensional (Webb, Nasco, Riley, \& Headrick, 1998). The Webb et al. (1998) model is comprised of two dimensions: public and private. An individual's private athlete identity is related to how an individual internalizes their role as an athlete and the resulting consequences on their self-definition. Conversely, the public dimension is a reflection of the individual's understanding of how others perceive him or her as an athlete. These dimensions indicate that there are external and internal components of one's athlete identity (Webb et al., 1998).

For many, one's athlete identity is likely to wane after he or she stops participating in competitive activities. Past scholars have confirmed that such a trend exists (Houle, Brewer, \& Kluck, 2010). Specifically, the age in which one's athlete identity begins to fade tends to be shortly after the completion of high school and within the years of attending colleges. This often coincides with the time in which an individual ceases to participate in competitive activities (Houle et al., 2010). In addition, it appears as if the connection to a team has an effect on one's athlete identity. Being removed or left off a team can negatively affect the athlete identity (Grove, Fish, \& Eklund, 2004), and staying involved with teams or sport organizations can positively affect athlete identity (cf. Shachar, Brewer, Cornelious, \& Petitpas, 2004). An eSports athlete could maintain an athlete identity via competing in eSports activities with teammates. Moreover, individuals with a high degree of athlete identity are likely to gain satisfaction or positively impact their self-esteem with impactful displays of athleticism (Callero, 1985). This could lead to an eSports athlete being able to reinforce their athlete identity by performing well while competing in an eSports competition. Further, a strong athlete identity could contribute to an increase in —and an accumulation of — social capital.

\section{Social Capital}

Social capital has been described as the resources that are gathered from social relations within a network or group of people and the subsequent benevolence (Adler \& Kwon, 2002; Nahapiet \& Ghoshal, 1998). Defined, social capital is “... a set of informal values or norms shared among members of a group that permits cooperating among them..." (Fukuyama, 1995, p. 16). Others have conceptualized the construct as the result of social networks within groups, and posited that the construct is a "good" that can be used to improve the standing of an individual within a group (Putnam, 2000). The value of the good is then dependent upon the quality of the social connections within the network. Moreover, as the singular members within the group begin to reap the benefits of the strong social network so too shall the entire group. This process does not occur in a singular moment, but rather it is developed over time (Putnam, 2000).

Putnam's (2000) seminal work on social capital within a community consisted of two related constructs: bonding and bridging social capital. Bonding social capital represents the connections between homogenous social networks. This form of social connections leads to the fortification of values and characteristics held by the group and its members. The fortification of the bonds between members of the network-via the shared values and characteristics-draws the members closer. However, the homogeneity of the network prompted Putnam (2000) to refer to bonding social capital as the darker side of social capital. That is, this form of 
social capital can lead to discrimination and exclusion from group membership. The potential negative effects of bonding social capital are not unlike groupthink or groups that are impenetrable from outside opinions or members. Bonding social capital would be exemplified when an eSports team subscribes to its own policies and procedures and resists adding new membership because the connections they share among one another are so rigid that it is nearly impossible to expand the social network.

Conversely, bridging social capital represents connections that cross the barriers of bonding social capital. Putnam (2000) explained that bridging social capital facilitates the creation and formation of links between heterogeneous groups of individuals within a social network. Although relationships formed in bridging social capital are often weaker than those formed in boding social capital, the superior bridging version of social capital enables the daily interactions between different groups of people. Restated, bridging social capital allows one to transcend the limitations of bonding social capital and connect with individuals or groups of people who have a diverse set of values and philosophies. In sum, bridging social capital allows diverse communities or groups to form. This can be seen with an eSports team when the team is comprised of different people from different background and perspectives, and the members of the team establish their own community (i.e., social network).

Throughout Putnam's articles detailing the role of social capital (Putnam, 1995; Putnam, 2000; Sander \& Putnam, 2010), the decline of group bowling participation is used as an example of declining social capital. Perks (2007) noted that it is then "Perhaps not surprising that Putnam has identified sport participation as one of the ways social capital can be generated" (p. 380). Further, Perks (2007) noted that sports can serve as a viable environment for building social capital because of the "associational nature" of sports, social capital can have an impact on community cohesiveness and social integration.

The unification of a diverse set of persons into a collective entity (i.e., a team) is a manifestation of social capital. In detailing the connection between local sport clubs and social capital, Nicholson and Hoye (2008) emphasized, "Local sports clubs are an important component of the formal and informal social networks that underpin the creation, development, and maintenance of social capital" (p. 188). The social capital that is gained from the formation of a team can provide benefits to the individual members of the team in a variety of manners. For example, being a member of a college sport team may offer individuals a link to the general campus community. Sport teams are particularly salient to the culture of the college community (Beyer \& Hannah, 2000). Furthermore, Clopton $(2007,2008)$ has explained how the accolades of sport teams contribute to the formation of the sense of community for colleges and universities. As such, being a member of a sport or eSports team is likely to provide an individual with social capital that can be used to advance them within the social network of the overall campus community. More specifically, the social capital processes within the team environment are likely to strengthen the individual's perceived role or place within the unit. This assertion is based on Clopton's (2011) finding that ethnic minority student-athletes-who attended a predominantly White institution-felt more comfortable when in the team setting. Clopton's (2011) findings suggest that the sense of team is critical for students who do not necessarily fit in with the rest of the campus community. 
This is especially relevant considering several of the participants brought up the commonly held stereotypes of being a nerd.

Thus, eSports athletes' team membership_and the subsequent social capital-may provide them with an outlet to the larger campus community. Perhaps more importantly, it may provide them with a socially safe environment. This safe environment would theoretically allow the eSports athletes-or any other marginalized population - to feel comfortable within a larger climate in which they are not traditionally accepted. Thus, when considering the interviewed eSports athletes' responses to questions on participation and continued involvement in eSports both during and after their collegiate experience, it is important to keep in mind the extent to which he or she identifies as an athlete, and his or her thoughts on the role participation in eSports affects his or her social capital.

Aligning with the overall purpose of this examination, the guiding research questions for this study are as follows:

(1) In what ways are eSports scholarship athletes similar and dissimilar to other more "typical" scholarship athletes?

(2) What role does having an eSports team build both bonding and bridging social capital for team members?

\section{Method}

Audio-only Skype interviews were conducted with 33 eSports student-athletes (32 males, 1 female; Table 1) at Colonial University (a pseudonym). The interview protocol and overall study received Institutional Review Board approval. Interviews were arranged through the head coach and director of operations of the eSports team and conducted by all authors. Each interview lasted approximately 15-20 minutes and no identifying information was collected. The sample was purposeful in acquiring student-athletes who (1) were on scholarship, (2) a mix of freshmen, sophomores, juniors, and seniors, and (3) varying skill levels. The interviews were scheduled and conducted during breaks in the team practice schedule. Once data saturation was achieved, participation acquisition was concluded. Gratton and Jones (2004) described data saturation as the stage, "where any further data collection will not provide any different information from that you already have, that is you are not learning anything new" (p. 153). In regards to reliability and validity, the study followed the five verification strategies posited by Morse, Barrett, Mayan, Olson, and Spiers (2002): methodological coherence, appropriate sample, collecting and analyzing concurrently, thinking theoretically, and theory development.

\section{Setting and Participants}

Due to the small number of institutions currently giving scholarships for eSports, this section is intentionally vague while still providing necessary background information on the setting and participants. Colonial University (a pseudonym) is a private institution with an enrollment below 10,000. The university sponsors over 20 sports that compete primarily at the NAIA level. The university is located in a metro area in the Midwest. Participants in the interviews below ranged from freshman in their first year on campus after graduating high school to seniors who 
Table 1 Demographic Information of Participants

\begin{tabular}{lll}
\hline Pseudonym & Gender & Year in School \\
\hline Noah & Male & Junior \\
Liam & Male & Freshman \\
Ethan & Male & Freshman \\
Lucas & Male & Freshman \\
Mason & Male & Freshman \\
Oliver & Male & Sophomore \\
Aiden & Male & Freshman \\
Elijah & Male & Freshman \\
Benjamin & Male & Freshman \\
James & Male & Senior \\
Logan & Male & Freshman \\
Jacob & Male & Sophomore \\
Jackson & Male & Sophomore \\
Michael & Male & Freshman \\
Carter & Male & Freshman \\
Luke & Male & Junior \\
Daniel & Male & Freshman \\
William & Male & Sophomore \\
Alexander & Male & Freshman \\
Owen & Male & Sophomore \\
Jack & Male & Freshman \\
Gabriel & Male & Freshman \\
Matthew & Male & Freshman \\
Henry & Male & Sophomore \\
Sebastian & Male & Senior \\
Wyatt & Male & Sophomore \\
Grayson & Male & Junior \\
Isaac & Male & Freshman \\
Emma & Female & Sophomore \\
Nathan & Male & Sophomore \\
Ryan & Male & Freshman \\
Jayden & Male & Freshman \\
Caleb & Senior \\
\hline & & \\
\hline
\end{tabular}


had been professional eSports athletes before attending the college. There was no consistent major for the participants but engineering, math, and undecided appeared the most frequently. Finally, the participants had all played eSports extensively before attending Colonial University.

\section{Instrument}

Based on the past literature (e.g., Brewer et al., 1993; Putnam, 2000; Webb et al., 1998), an interview guide was developed by all authors and used to direct the interviews (Johnson \& Christensen, 2008). The format was semistructured in nature to allow for deeper examination of topics based on the responses of the subjects. Questions asked of all respondents included: (1) Could you describe your gaming background before coming to college? (2) Did you participate in other competitive activities growing up? (3) What is a common reaction when you tell someone you are a scholarship eSports athlete? (4) How do you feel wearing the athletic apparel on campus? (5) Please describe your relationship with other athletes in the department. (6) How do you think your eSports activity will change beyond graduation? (7) What makes the time you put into this worthwhile?

\section{Analysis}

An open coding approach, as suggested by Corbin and Strauss (2008), was used. Corbin and Strauss (2008) argued open coding is beneficial because, "though we break data apart, and identify concepts to stand for the data, we also have to put it back together again by relating those concepts" (p. 198). Procedurally, the researchers adhered to Gratton and Jones' (2004) four-part coding framework. In accordance with Stage One, the authors carefully read all transcribed interviews and then assigned each interviewee response to each question a "code" - a word or several words to describe the response. This process is known as "open coding" (Gratton \& Jones, 2004, p. 220). Each of the coding authors independently open coded the data. Then, each author entered a summary of his or her codes into a shared Microsoft Word document. The authors then followed Gratton and Jones “ (2004) second stage of the four-part coding framework. In this stage, "the researcher rereads the qualitative data, and searches for statements that fit into any of the (Stage One) categories" (Gratton \& Jones, 2004, p. 220). In this stage, also known as axial coding, the authors met and collectively discussed representative interviewee responses that fit into the categories discussed in Stage One. In Stage Three, the authors are to "become more analytical, and look for patterns and explanations in the codes" (Gratton \& Jones, 2004, p. 220). During this stage, the authors collectively discussed how the deductive themes fit with established theory and how the inductive themes could be organized to most appropriately show new directions that emerged from the data. In Stage Four, known as selective coding, the authors are to reread the raw data for cases that illustrate the analysis. In this stage, the authors discussed whether the representative quotes from Stage Two also aligned with the established theoretical connections to the data from Stage Three. Representative quotes from Stage Four of Gratton and Jones' (2004) four-part coding framework are presented verbatim throughout the Findings and Discussion section. 
To illustrate how the raw data were coded and then collapsed into themes, consider the following process for how the authors adhered to Gratton and Jones (2004) four-part coding framework to finalize the themes of bonding and bridging social capital. Two of the questions were, "Could you describe the team dynamics of your eSports team?" and "Could you describe your relationships with other athletes in the athletics department?" Each author transcribed verbatim the interviewees he or she conducted and open coded interviewee responses. For the two aforementioned interview questions, open code tags included "friends outside of practice," "some are roommates," "stick together," "eat together," and "not really friends with other athletes." Authors met to discuss the open codes, then together discussed representative interviewee responses, which adheres to the axial coding of Stage Two. These responses are currently included in the Findings and Discussion section. To follow Stage Three, the authors looked for analytical patterns and discussed that interviewee responses for the two questions seemingly aligned with social capital, and more specifically, bonding and bridging social capital. In Stage Four, the authors reread the raw data and decided that the representative quotes selected as part of Stage Two aligned with the bonding and bridging social capital analysis from Stage Three. In the Findings and Discussion section, these themes and the relationship to bridging and bonding social capital are discussed.

The deductive themes (detailed in the following section) used to initially group responses included athlete identity, social capital, and connection to the university. Inductive themes that came from additional analysis of the data were interest in continuing eSports participation and the eSports team atmosphere, among others. The deductive themes came from the previous literature used as background for the interview prompt while the inductive themes emerged from all authors identifying data not described in the background literature. Below, the responses are both summarized and presented verbatim to allow for the voice of the participants. The quotes presented were chosen to best represent the breadth of responses within each theme from the participants.

\section{Trustworthiness}

Shenton (2004) suggested certain steps qualitative researchers can take to meet the quality criterion of credibility, transferability, dependability, and confirmability. Each of these constructs corresponds to more positivist approaches. Specifically, it is argued that credibility aligns with internal validity, transferability with external validity, dependability with reliability, and confirmability with objectivity (Shenton, 2004). When taken together, these criterion address trustworthiness of the qualitative methodological approach undertaken (Shenton, 2004).

In this study, three of Shenton's (2004) specific provisions were used to meet the credibility criterion. These provisions were (1) the development of an early familiarity with the culture of participating organizations, (2) the adoption of well-established qualitative research methods, and (3) triangulation. The corresponding author conducted several phone calls and exchanged emails with the eSports coach to gain a better understanding of the operations of the eSports team within Colonial University's athletics department structure. Information from the preliminary communication served to help develop the interview guide. One-on-one interviews are the most common type of interview within social science research 
(Andrews, Mason, \& Silk, 2006), which aligns with Shenton's (2004) emphasis to use well-established qualitative methods to establish credibility. While triangulation most typically involves using multiple methods for data collection, "another form of triangulation may involve the use of a wide-range of information" (Shenton, 2004, p. 66). In this study, thirty-three subjects were interviewed and data saturation was achieved.

Provision strategies were also used for the other three provision strategies of transferability, dependability, and confirmability. Specifically for transferability, it is important to use background data "to establish context of study and detailed description of phenomenon in question to allow comparisons to be made" (Shenton, 2004, p. 73). We have sought to provide a detailed background of the eSports context before detailing interviewee responses. For dependability, it is important that the methodology is described in detail to allow for the study to potentially be repeated by other researchers (Shenton, 2004). Lastly, for confirmability, it is important for the researchers to recognize shortcomings of the study's methods and the potential consequences of such shortcomings. These issues are addressed when discussing the limitations of the study before the Conclusion section. In all, we believe the criterion of credibility, transferability, dependability, and confirmability and the associated provision strategies address the trustworthiness of the current examination of eSports scholarship athletes.

\section{Findings and Discussion}

In this study, the authors aimed to better understand eSports athletes participating on scholarship at the intercollegiate level. After interviewing 33 eSports athletes, several themes emerged regarding their experience participating on a college eSports team. Specifically, athlete identity and social capital emerged as the most salient themes (Table 2). Further, such themes could potentially have direct implications on the role eSports can have in the overall university, as will be discussed in the conclusions section. To further discuss the responses of our participants, this section has been broken down into sections consistent with past literature on athlete identity and social capital.

\section{Athlete Identity}

Many of the interview questions were designed to assess how the interviewees view themselves as athletes. Their responses were categorized in three sections: (1) athletic background, (2) public and private perceptions as an athlete, and (3) interest in continuing eSports beyond college.

eSports Athlete Background. Many interviewees had either a gaming (i.e., eSports) and/or traditional sport background. James (pseudonym) represented a general consensus among many participants when he said:

Prior to getting here, I was a pretty avid gamer. I've been playing League [of Legends] for about four years so it just kind of built from there. I've always been a gamer since I was young. Like since I was five or six. I was on the basketball team, soccer team, and track team. 


\section{Table 2 Codes Derived From the Data}

\begin{tabular}{|c|c|c|}
\hline Primary Codes & Secondary Codes & Initial Themes \\
\hline \multicolumn{3}{|l|}{ Athlete Identity } \\
\hline & eSports Athlete Background & $\begin{array}{l}\text { Many interviewees had either a gaming } \\
\text { (i.e., eSports) and/or traditional sport } \\
\text { background; also participated in other } \\
\text { extracurricular activities (e.g., band) }\end{array}$ \\
\hline & $\begin{array}{l}\text { Public and Private Perception as } \\
\text { an Athlete }\end{array}$ & $\begin{array}{l}\text { Most interviewees self-identified as ath- } \\
\text { letes, and even went out of their way to } \\
\text { defend their position as an athlete; indi- } \\
\text { cated high time commitment required to } \\
\text { develop skills; discussed "nerd" stereo- } \\
\text { types of gamers }\end{array}$ \\
\hline & $\begin{array}{l}\text { Interest in Continuing eSports } \\
\text { Participation }\end{array}$ & $\begin{array}{l}\text { Nearly all participants expressed a desire } \\
\text { to be involved in eSports in some capac- } \\
\text { ity, and many stated that playing profes- } \\
\text { sionally was their main goal beyond } \\
\text { graduation; interest in coaching or serv- } \\
\text { ing as a game analyst }\end{array}$ \\
\hline \multicolumn{3}{|l|}{ Social Capital } \\
\hline & Social Capital in eSports & $\begin{array}{l}\text { Social capital was attained within the } \\
\text { team setting, but participants' social capi- } \\
\text { tal network did not extend to other teams } \\
\text { at Colonial University }\end{array}$ \\
\hline & eSports Team Atmosphere & $\begin{array}{l}\text { Every participant stated that he or she } \\
\text { had formed strong lasting relationships } \\
\text { with other members of the team; family- } \\
\text { type atmosphere; new eSports experience } \\
\text { of being in same physical location as } \\
\text { teammates and practice partners }\end{array}$ \\
\hline & $\begin{array}{l}\text { Connection to the Colonial Uni- } \\
\text { versity Athletics Department }\end{array}$ & $\begin{array}{l}\text { While some interviewees stated that they } \\
\text { were friends with athletes from other } \\
\text { teams, a general consensus was reached } \\
\text { that the eSports team was very much } \\
\text { separated from the rest of the athletics } \\
\text { department; tension from other athletes } \\
\text { about eSports athletic scholarships; lack } \\
\text { of athletics department recognition of } \\
\text { eSports success }\end{array}$ \\
\hline
\end{tabular}

It was also important to discover why the eSports athletes chose to go to school at Colonial University and what impact the eSports program and/or scholarship had on their school decision. This helped to establish how important eSports were in the decision-making process. A majority of the interviewees chose to attend Colonial University at least in part because of the opportunity to be a part of the eSports program. The prospect of receiving a scholarship to play eSports as well 
as Colonial University being among the top eSports programs in the country influenced many participants' decision on where to attend. Noah expressed the following regarding his decision to attend Colonial University, which was representative of most interviewees:

I was really into League of Legends so that's the only reason I came to [Colonial University]. They had a scholarship and I wanted to play competitively with a team and that was basically the main decision. I had offers from other schools, but it was just straight up League of Legends, that's pretty much what I wanted to do.

Public and Private Perceptions as an Athlete. Athlete identity explains the extent to which the role of athlete is important to an individual when compared with their other social roles (Brewer et al., 1993). Research on athlete identity has indicated a multidimensional construct, consisting of both a private and public dimension (Webb et al., 1998). The present research revealed the dramatic difference between the two dimensions in eSports athletes.

Consistent with the literature on athlete identity (Webb et al., 1998), results were analyzed in terms of how the interviewees internalized their role as an athlete as well as their understanding of how others perceived them as an athlete. Most interviewees self-identified as athletes, and even went out of their way to defend their position as an athlete. Elijah said, "As far as I'm concerned, it's a sport. You gotta (sic) practice six hours a day, six days a week" and followed that up by emphasizing, "I do consider myself an athlete, it's not athletic or physically demanding but I am practicing quite a lot to play this game at a competitive level."

Interviewees were also asked about how they feel wearing the Colonial University athletics department issued apparel on campus as indicated by Gabriel who representatively said, "I'm proud of it. The amount of time that I have put into this game and work I have put it, I am proud to be on this team." Aiden conveyed similar ideas about wearing Colonial University athletic apparel on campus by saying:

I feel like I am representing [Colonial University] as well as eSports, so I'm kind of showing people that this is a team, it's real, what we do is legit. It is just me expressing that this is who I am and this is what we do at school and what we do isn't easy so give us some type of respect.

As far as outside perceptions of their role as an athlete, most participants acknowledged that other athletes and students do not necessarily view them as athletes. James expressed this sentiment regarding outsider stereotypes of eSports athletes by saying,

A lot of people stereotype eSports players as fat basement dwelling neckbeards that have no life, but everyone here is just normal people that love the game. I think a lot of times we prove that stereotype wrong on a daily basis.

The idea that they are able to 'prove a stereotype wrong' or change people's perceptions of them was shared among the interviewees. Most participants believed that by getting to know others better that they could alter the stereotypes. Elijah represented the quotes of his eSports teammates when he said, "It takes sitting down and talking to these people to explain what we are doing and get to a personal 
level. We really aren't (sic) that different." While most acknowledged that negative stereotypes exist that depict them as nonathletes, nearly all participants explained that they were able to overcome those stereotypes.

The private dimension of athlete identity references how individuals internalize their role as an athlete (Webb et al., 1998). Internally, most participants identified as athletes. In the face of stereotypes and perceptions, many defended their role as an athlete, with some even going out of their way to reinforce their athlete identity. The nature of eSports, where physical movement is limited, leads to criticism when categorized as a sport. Despite these sentiments, almost all of the interviewed eSports athletes remained steadfast in their identification as athletes. Only one eSports athlete said in an outright manner that he did not view himself as an athlete.

Alternatively, the interviewees acknowledged that people outside of the eSports community rarely identified them as athletes, or eSports, as a true sport. Most participants stated that while they personally identified as an athlete because of the skill needed to compete at a high level and the amount of time they put into eSports, outsiders did not agree because of the nonphysical nature of the game. As a newly established college sport, the public dimension of eSports athletes' athlete identity would likely consist of other athletes' acceptance of them. However, the participating eSports athletes believed that athletes from other sports at Colonial University failed to perceive them as traditional athletes. As a result, eSports athletes tended to feel disconnected from the rest of the athletics department.

Interest in Continuing eSports Participation. The participants shared similar sentiments regarding their future beyond graduation that many college athletes in traditional sports maintain. Nearly all participants expressed a desire to be involved in eSports in some capacity, and many stated that playing professionally was their main goal beyond graduation. James said, "If I couldn't become a pro player, I would just want to help people who have been in my position." James was then asked if playing professionally was his goal, and responded "Yeah, that's everyone's dream." Even when they knew it was unrealistic that they might become a professional player, most interviewees expressed interest in being involved in eSports as a coach, commentator, or in some other capacity. This was conveyed when a Gabriel representatively said,

I definitely want to be involved. I am hoping that after I graduate I will be good enough and move up high enough that I can join a team or maybe become an apprentice and just be a part of the community. If I can't play maybe just being a coach or coaching online for players to get better I feel like that could be an avenue I pursue. I just really want to be a part of the community.

A majority of participants expressed a desire to continue involvement with eSports beyond graduation. Most interviewees agreed that the main goal for eSports athletes was to play professionally once their time at the school was over. Many of the athletes stated that the competition and relationship building aspects of eSports are what makes them want to continue involvement. Some participants that conceded the difficulty of playing professionally stated that if they were not able to continue playing they would attempt to be a coach or analyst for the program.

Much like other athletes with an intense connection to sport (cf. Shachar et al., 2004), eSports athletes demonstrated an interest in extending their involvement 
in eSports activities beyond the competitive collegiate experience. This can be interpreted as an attempted to ward off a decline in their identity as an athlete. Such findings are consistent with previous findings on athlete identity (see Grove et al., 2004; Houle et al., 2010; Shachar et al., 2004). eSports as a career and the comparison between eSports and traditional sport in the area of athlete involvement beyond the completion of collegiate eligibility could be a potential research topic in the future.

\section{Social Capital}

Social Capital in eSports. Data regarding social capital in eSports athletes fell into two distinct categories: (1) social capital within the eSports team, and (2) social capital outside of the eSports team. Such results align with bonding social capital (social capital within homogeneous group members) and bridging social capital (social capital across heterogeneous groups and group members). It was found that for eSports players social capital was attained within the team setting, but participants' social capital network did not extend to other teams at Colonial University.

eSports Team Atmosphere. A new aspect for many of the interviewees was playing League of Legends as a team rather than as a collection of individuals. Every participant stated that he or she had formed strong lasting relationships with other members of the team. Nathan represented the views of the team members by saying,

I just got to know these guys and so far so good. I like all of my teammates. I think the biggest misconception is like when you hear about a gaming team, you think about a bunch of weird kids or a bunch of nerds, but I think all of the guys here on my team are really down to earth and they are just cool guys to hang out with.

Aiden even likened the eSports team at Colonial University to a family, and expressed a general sentiment about the team dynamic by saying,

Within [Colonial University] all our teams are like a big family, collectively we don't bring each other down, we tell each other what they can work on, what they did amazingly, what they need help on. We just build each other up, I don't think we ever break anyone down.

As mentioned previously, the idea of participating on an eSports team where teammates were in the same physical location (as opposed to participating in eSports with teammates in remote locations) was a new experience for the eSports athletes at Colonial University. Such a notion aligned with Tonts' (2005) exploration of competitive sport and social capital in rural Australia. Specifically, it was emphasized that "There is also likely to be a geographical dimension to the relationship between social capital and sport. This is particularly true for team sports that are anchored to particular places" (p. 139). Importantly, these eSport athletes were newly anchored to a geographical location at Colonial University for their eSports participation. As such, the relationships they were able to build with their teammates were likely aided in part by the geographical proximity to their teammates-a notion that is not 
necessarily always true in a sport where competition is often conducted between opponents that need not be in the same physical locale for the competition to take place. Both the association nature (Perks, 2007) and the geographical proximity (Tonts, 2005) of the team seemingly aided in building social capital within the eSports team at Colonial University.

Connection to the Colonial University Athletics Department. While most participants felt a strong connection to their eSports team at Colonial University, the same cannot be said about their feeling of connectedness to the other sports teams and the athletics department as a whole. While some interviewees stated that they were friends with athletes from other teams, a general consensus was reached that the eSports team was very much separated from the rest of the athletics department. Elijah conveyed feelings similar to his teammates when he said, "There is a little bit of tension there and disconnectedness from the rest of them (other athletes) to be honest with you. A lot of them don't really get what we are doing and just don't have that kind of understanding." James expressed a similar sentiment when he said, "Zero connection. Some people think that we are like a real sports program and then some people think it's a joke. Usually other athletes in class are like the typical jocks."

A clear dichotomy existed between the ability of eSports athletes to build social capital within their team and throughout the athletics department as a whole. A strong relationship existed among the eSports athletes but was not present between the eSports athletes and athletes from other teams. An important aspect of participating on a sports team, particularity at the collegiate level, is the ability to gain social capital through one's inclusion in that social group. Collegiate athletes have shown a unique ability on college campuses to obtain social capital through their sports participation (Clopton, 2011). In light of their new positions as collegiate student-athletes and the results pertaining to their athlete identity, it was important to examine further if eSports athletes maintained a similar ability to obtain social capital as traditional athletes. Consistent with the results on social capital, it was found that eSports athletes were able to gain social capital within their team, but not outside of their team, and specifically not through relationships with other athletes (cf. Clopton, 2011). This limits the potential benefits of bridging social capital as access to diverse and beneficial social networks were unrealized (Putnam, 2000). As such, the homogenous network of shared values and characteristics within their team indicated the social connections for participants resembled Putnam's (2000) bonding social capital.

The eSports athletes indicated a presence of both the positive and negative aspects of bonding social capital. Specifically, Putnam (2000) explained that bonding social capital represents the idea that the fortification of bonds between likeminded group members enhances shared values and characteristics and draws the members closer. The eSports athletes demonstrated high levels of bonding social capital within their team. However, such high levels of social capital are indicative to what Putnam (2000) called the negative side of bonding social capital. Such a build-up of in-group social capital led to some exclusionary feelings between the eSports team and other athletes and the athletics department overall. Despite the positive nature of the social relationships formed within the eSports team, bridging social capital seemingly failed to exist with regard to the remainder of the athletes 
at Colonial University because of the heterogeneity between eSports athletes and the other more traditional sports teams. According to the interviews with eSports athletes, traditional sports teams exercised bonding social capital, in which the relationships of athletes participating in traditional sports were strengthened, but simultaneously eSports athletes felt excluded from the group (i.e., traditional student-athletes). This lack of access to the larger social network-represented by the other teams within the athletics department - signaled a barrier for participants to benefit from interactions with other individuals (i.e., bridging social capital). Restated, there was a lack of bridging social capital between the eSports team and other traditional sport teams. This is exemplified when eSports athletes reported feelings of disconnectedness from the remainder of the athletics department and relatively few interviewees stated that they had formed meaningful relationships with other athletes outside of eSports.

Liam, when discussing any connectedness to the athletics department, lamented

They (the athletics department) don't really give us recognition. Our team got $\$ 90,000$ in scholarship (tournament winnings) last year and we're at the athletic meeting and they didn't even shout us out and they would shout out our softball team for getting seventh in state or something. You know, and you've got the best League (of Legends) team in the country and no - they don't say anything.

Most interviewees expressed sentiment that participating on the eSports team at Colonial University was a positive experience in which they have developed strong friendships with many of their teammates. Further, because for many of the interviewees, their participation on the Colonial University eSports team is their first time being a part of any eSports team, the ability to create these connections is a relatively new phenomenon. The social capital gained through these relationships can be invaluable, particularly for an individual who has not had access to these social avenues in the past. Further, the eSports athletes felt that the high levels of social capital within the eSports teams helped to compensate for the overall lack of social capital with other, more traditional sports teams on campus-a finding that is similar to Clopton's (2011) work.

This study is not without its limitations. Specifically, this study was only based on the experiences of eSports athletes from one institution. Further, results were based only on semistructured interviews with the eSports athletes. In addition, the interviewee sample notably included only one female. While we believe that inclusivity and social gains were part of the experiences of the interviewed eSports players, it was difficult to determine any gender differences because of the small female sample size. Based on several popular press articles indicating both the underrepresentation and marginalization of female eSports players (Campbell, 2015; Odyssevs, 2016), future research should examine the positive and negative experiences of female eSports athletes. Such future research is particularly important in light of Gamergate, now considered "an Internet culture war" surrounding the inclusion of female eSports athletes (Dewey, 2014, para. 6). In addition, future research could help to address the aforementioned limitations by (1) conducting in-person observations of the eSports athletes, (2) interviewing eSports athletes at other institutions, and (3) learning more about eSports from the perspectives of coaches, athletics directors, or campus administrators. 


\section{Conclusion}

Overall, findings indicated that the eSports athletes had high levels of athlete identity and also high levels of social capital within the insular structures of their team, findings that aligned with Putnam's (2000) work on bonding and bridging social capital. However, public perceptions of eSports as nonathletes and a lack of bridging social capital between the eSports team and other teams in the athletics department indicated a strong disconnect. This occurrence prevented participants from expanding their social networks to more heterogeneous groups, which subsequently could have improved their social standing via bridging social capital. Importantly, the positive aspects of high athlete identity and high social capital (e.g., fortification of bonds, strengthening of values, strong team environment) seemingly compensated for the negative aspects of public perception and little bridging social capital (e.g., disconnect with athletes on other teams and the athletics department overall). The authors argue the aforementioned negative aspects are somewhat mitigated due to the eSports athletes spending the vast majority of their outsideof-class time with their teammates - people who enhance their athlete identity and build up their social capital. Therefore, for this specific set of eSports athletes, the idea that the accrued social capital enhanced the overall college experiences of the eSports athletes aligned with previous research connecting sports participation and enhanced social capital (Clopton, 2011).

Further, one salient theme emerged that very much aligns with more traditional elite level athletes - the desire to go pro. Participants indicated that they not only had a desire to go pro after their college-level eligibility expired, but that there was an interest in going pro early (i.e., before graduating) to capitalize on an individual's finite time window (due to stamina and finger dexterity) to gather more financial capital as a professional eSports competitor. This finding is representative of athlete identity. Placing a greater emphasis on their role as an eSports athlete-as demonstrated by their willingness to leave school before graduating - serves to cement their internal and external (i.e., private and public) self-definition as an athlete. In turn, this action (i.e., leaving school before graduating) fortifies their athlete identity.

The analysis of athlete identity and social capital for eSports in the current study presents potential for several practical implications for athletics administrators and coaches, as well as eSports athletes and traditional student-athletes. By understanding the combined value of these dynamics and their relation with prior research on bonding and bridging social capital (Putnam, 2000) and enhanced social capital as a result of campus sport team membership (Clopton, 2011), we believe it could be relevant to examine the impact of eSports on administrative decision-making in future studies at institutions with small enrollments. Many respondents specifically mentioned eSports as the influential driver in choosing to attend Colonial University, and the benefits associated with athlete identity and social capital further enhance retention.

Athlete identity and social capital provide a foundation for the eSports studentathlete to effectively transition to college life, and this was reinforced with the participant responses pertaining to taking pride in representing the university and forming relationships with fellow eSports athletes. By utilizing this insight on eSports student-athletes, coaches and administrators can effectively capitalize on 
sponsorship of this sport as a competitive varsity program, while strengthening the campus community as a whole.

Importantly, the findings from this research study help to assess the seven-prong test we used for assessing whether an activity is a sport (Guttmann, 1978; Jenny et al., 2016; Suits, 2007). Specifically, the results reinforce that eSports meets five of the seven characteristics (e.g., includes play, is organized, includes competition, comprises skill, and has a broad following). Notably, the authors also argue that the current results further address the two debatable characteristics of eSports qualifying as a true sport: whether it includes physical skills and whether it has achieved institutional stability. The interviewed eSports athletes felt the both the physical stamina required to practice for such long hours and the paramount importance of skilled finger dexterity (as well as how declining dexterity dramatically shortened the length of prime years of gaming) contributed to their perceptions of eSports being a true sport. In relation to the last prong of the characteristics required of a true sport-achieving intuitional stability-the authors argue that the continued growth of all forms of sport actually necessitates instability. That is, the multitude of enterprises competing for eSports revenues (Jenny et al., 2016) are no different than the various enterprises competing for merchandise contracts or broadcasting rights contracts in the NCAA, the National Basketball Association, or the National Football League (see Brady, 2016; Rocco, 2015; Rovell, 2014; Rovell, 2015). Such an understanding serves two essential purposes. First, it provides further justification for eSports meeting qualifications for being defined as a sport. Second, the seemingly comparable interests in commercialization of eSports (either from a professional or college enrollment perspective) and in traditional sport indicate that further research should be conducted to examine the viability of eSports as an officially sanctioned sport at the college level.

\section{References}

Andrews, D. L., Mason, D. S., \& Silk, M. L. (2006). Qualitative methods in sports studies. Oxford: Berg.

Augustine, B. (2015, April 27). ESPN2 airs video game tournament, Heroes of the Dorm, viewers freak out. Retrieved from http://www.nydailynews.com/sports/viewersfreak-espn2-airs-video-game-tournament-article-1.2200403

Adler, P.S., \& Kwon, S-W. (2002). Social capital: Prospects for a new concept. Academy of Management Review, 27(1), 17-40.

Beyer, J.M., \& Hannah, D.R. (2000). The cultural significance of athletics in US higher education. Journal of Sport Management, 14(2), 105-132. doi:10.1123/jsm.14.2.105

Brady, E. (2016, April 12). NCAA extends tournament deal with CBS, Turner through 2032 for $\$ 8.8$ billion. USA Today. Retrieved from http://www.usatoday.com/story/sports/ ncaab/2016/04/12/ncaa-contract-extension-cbs-turner-ncaa-tournament-march-madness/82939124/

Brewer, B.W., Van Raalte, J.L., \& Linder, D.E. (1993). Athletic identity: Hercules' muscles or Achilles heel? International Journal of Sport Psychology, 24, 237-254.

Callero, P.L. (1985). Role-identity salience. Social Psychology Quarterly, 48, 203-215. doi:10.2307/3033681

Campbell, C. (2015, November 3). Smite, sexism, and the soul of eSports. Polygon. Retrieved from http://www.polygon.com/features/2015/11/3/9660094/smite-sexism-and-thesoul-of-esports 
Casselman, B. (2015). Resistance is futile: eSports is massive ... and growing. ESPN The Magazine. Retrieved from http://espn.go.com/espn/story/_id/13059210/esportsmassive-industry-growing

Clopton, A.W. (2007). Predicting a sense of community amongst students from the presence of intercollegiate athletics: What roles do gender and BCS-affiliation play in the relationship? The Sport Management and Related Topics Journal, 4(1), 95-110.

Clopton, A.W. (2008). College sports on campus: Uncovering the link between fan identification and sense of community. International Journal of Sport Management, 9, 1-20.

Clopton, A.W. (2011). Using identities to explore social capital differences among White and African American student athletes. Journal of African American Studies, 15(1), 58-73. doi:10.1007/s12111-010-9121-6

Coakley, J. (2007). Sport in Society: Issues and Controversies. New York: McGraw-Hill.

Corbin, J., \& Strauss, A. (2008). Basics of qualitative research: Techniques and procedures for developing grounded theory (3rd ed.). Thousand Oaks, CA: Sage. doi:10.4135/9781452230153

Dewey, C. (2014, October 14). The only guide to Gamergate you will ever need to read. The Washington Post. Retrieved from https://www.washingtonpost.com/news/the-intersect/ wp/2014/10/14/the-only-guide-to-gamergate-you-will-ever-need-to-read/

Ferrari, S. (2013). From generative to conventional play: Moba and league of legends. Proceedings of DiGRA 2013: DeFragging Game Studies, 1(1), 1-17.

Fukuyama, F. (1995). Trust: The social virtues and the creation of prosperity. New York, NY: Free Press.

Gaudiosi, J. (2015, May 28). At these two colleges, students can get scholarships for playing video games. Retrieved from http://fortune.com/2015/05/28/college-esportsscholarships/

Good, O. (2015, October 31). Missouri college to offer scholarships to skilled League of Legends players. Retrieved from http://www.polygon.com/2015/10/31/9650426/ esports-scholarships-columbia-college-league-of-legends-missouri

Gratton, C., \& Jones, I. (2004). Research methods for sport studies. New York: Routledge.

Grove, J.R., Fish, M., \& Eklund, R.C. (2004). Changes in athletic identity following team selection: Self-protection versus self-enhancement. Journal of Applied Sport Psychology, 16, 75-81. doi:10.1080/10413200490260062

Guttmann, A. (1978). (Vol. 107. From ritual to record. New York: Columbia University Press.

Houle, J.L.W., Brewer, B.W., \& Kluck, A.S. (2010). Developmental trends in athletic identity: A two-part retrospective study. Journal of Sport Behavior, 33, 146-159.

Jenny, S.E., Manning, R.D., Keiper, M.C., \& Olrich, T.W. (2016). Virtual(ly) Athletes: Where eSports fit within the definition of "sport". Quest, 1-18.

Johnson, B., \& Christensen, L. (2008). Educational research: Quantitative, qualitative, and mixed approaches (3rd ed.). Los Angeles: Sage Publications.

Jonasson, K., \& Thiborg, J. (2010). Electronic sport and its impact on future sport. Sport in Society, 13(2), 287-299. doi:10.1080/17430430903522996

Kelly, J. (2015, November 13). North American Collegiate Championship 2015-2016. Retrieved from http://esportsedition.com/league-of-legends/north-american-collegiatechampionship-2015-2016/

Morse, J.M., Barrett, M., Mayan, M., Olson, K., \& Spiers, J. (2002). Verification strategies for establishing reliability and validity in qualitative research. International Journal of Qualitative Methods, 1(2), 13-22. doi:10.1177/160940690200100202

Nahapiet, J., \& Ghoshal, S. (1998). Social capital, intellectual capital, and the organizational advantage. Academy of Management Review, 23, 242-266.

Nicholson, M., \& Hoye, R. (Eds.). (2008). Sport and social capital. Routledge.

Odyssevs, E. (2016, July 12). Why there are no female pro players. Daily ESports. Retrieved from http://www.dailyesports.tv/why-there-are-no-female-pro-players/ 
Perks, T. (2007). Does sport foster social capital? The contribution of sport to a lifestyle of community participation. Sociology of Sport Journal, 24(4), 378-401. doi:10.1123/ ssj.24.4.378

Putnam, R.D. (1995). Bowling alone: America's declining social capital. Journal of Democracy, 6(1), 65-78. doi:10.1353/jod.1995.0002

Putnam, R.D. (2000). Bowling alone: The collapse and revival of American community. New York, NY: Simon and Schuster. doi:10.1145/358916.361990

Robertson, C. (2015). Wandering the World without Leaving Your Chair: Crossing Borders Through eSports. University Honors Program Theses. Paper 104.

Rocco, M. (2015, July 21). TV deals boost NFL revenue to new record. Fox Business. Retrieved from http://www.foxbusiness.com/features/2015/07/21/tv-deals-boost-nflrevenue-to-new-record.html

Rovell, D. (2014, January 21). Under Armour signs Notre Dame. ESPN. Retrieved from http://espn.go.com/college-football/story/_id/10328133/notre-dame-fighting-irisharmour-agree-most-valuable-apparel-contract-ncaa-history

Rovell, D. (2015, July 11). NBA signs deal with Nike; logo to appear on uniforms. ESPN. Retrieved from http://espn.go.com/nba/story/_id/13053413/nba-signs-8-year-appareldeal-nike

Sander, T.H., \& Putnam, R.D. (2010). Still bowling alone?: The post-9/11 split. Journal of Democracy, 21(1), 9-16. doi:10.1353/jod.0.0153

Schuck, R.I. (2010). The Rhetorical Lines on TV's Poker Face: Rhetorical Constructions of Poker as Sport. The American Behavioral Scientist. doi:10.1177/0002764210368088

Schütz, M. (2016). Science shows that eSports professionals are real athletes. Deutsche Welle. Retrieved from http://www.dw.com/en/science-shows-that-esports-professionalsare-real-athletes/a-19084993

Shachar, B., Brewer, B.W., Cornelious, A.E., \& Petitpas, A.J. (2004). Career decision-making, athletic identity, and adjustment difficulties among retired athletes: A comparison between coaches and non-coaches. Kinesiologia Slovenica, 10, 71-85.

Shenton, A.K. (2004). Strategies for ensuring trustworthiness in qualitative research projects. Education for Information, 22(2), 63-75. doi:10.3233/EFI-2004-22201

Suits, B. (2007). The elements of sport. Ethics in sport, 2, 9-19.

Tassi, P. (2014, October 19). 40,000 Korean Fans Watch SSW Win 2014 'League of Legends' World Championship. Retrieved from http://www.forbes.com/sites/ insertcoin/2014/10/19/40000-live-korean-fans-watch-ssw-win-2014-league-of-legendsworld-championship/

Taylor, T.L. (2012). Raising the Stakes: E-sports and the Professionalization of Computer Gaming. Mit Press.

Tonts, M. (2005). Competitive sport and social capital in rural Australia. Journal of Rural Studies, 21(2), 137-149. doi:10.1016/j.jrurstud.2005.03.001

University of Pikeville. (2014, December 19). UPIKE enters the arena with new ESPORTs program. Retrieved from http://www.upike.edu/News/Campus/UPIKE-enters-thearena-with-new-ESPORTs-program

Wagner, M. (2007). Competing in metagame gamespace. Space Time Play, 182-185.

Webb, W.M., Nasco, S.A., Riley, S., \& Headrick, B. (1998). Athlete identity and reactions to retirement from sports. Journal of Sport Behavior, 21(3), 338-362. 